\title{
Contextos, processos e memórias: narrativas sobre saúde mental nas décadas de sessenta a oitenta no Brasil
}

\section{Contexts, processes and memory: narratives about mental- healthcare from the 1960's to the 1980's in Brazil}

\section{Helena Beatriz Kochenborger Scarparo}

Pontifícia Universidade Católica do Rio Grande do Sul, Porto Alegre, RS, Brasil

\section{Adolfo Pizzinato}

Pontifícia Universidade Católica do Rio Grande do Sul, Porto Alegre, RS, Brasil

\author{
Aline Accorssi* \\ Pontifícia Universidade Católica do Rio Grande do Sul, Porto Alegre, RS, Brasil
}

\begin{abstract}
RESUMO
Este artigo relata resultados parciais de pesquisas que vem sendo desenvolvidas, na dimensão da História Social, acerca dos processos de instituição da Psicologia no Brasil. No presente texto, partimos de memórias sobre as práticas no campo da saúde mental e tecemos considerações acerca do contexto brasileiro nos anos sessenta, setenta e oitenta, especialmente no que se refere à práticas desenvolvidas no Rio Grande do Sul. Dentre as abordagens utilizadas para apoiar a realização do estudo ressalta-se a história oral com a coleta de narrativas. Essas foram associadas a outros documentos e materiais midiáticos. A partir desse corpus se efetivou a análise. Dentre os resultados obtidos destaca-se a influência da Psiquiatria Comunitária e a relevância de experiências prévias de saúde comunitária para a consecução de transformações nas concepções e práticas de saúde e, mais especificamente, nas políticas de saúde mental brasileiras.
\end{abstract}

Palavras-chave: Saúde Mental, História, Políticas públicas.

\begin{abstract}
This article reports partial results of researches that are being developed, in the Social History dimension, about the institutionalization processes of Psychology in Brazil. In this text, we discuss memories of the mental healthcare practices and build considerations about the Brazilian context of the 1960s, '70s and '80s, specially concerning the practices developed in Rio Grande do Sul state. Among the approaches utilized to sustain this study, oral history with narrative collection is preeminent. These narratives were associated with documents and mediatic material. From this corpus, the analysis of the narratives that were in the practices of mental healthcare in the period mentioned above were effectuated. Among the results obtained, are highlighted: the influence of Community Psychiatry and the relevance of previous community healthcare experiences for the attainment of changes in conceptions and practices of health and, more specifically, in the Brazilian mental healthcare policies.
\end{abstract}


Keywords: Mental healthcare, History, Public policies.

\section{I ntrodução}

As memórias sobre o contexto brasileiro durante os anos sessenta descrevem períodos que mesclam repressão política, estratégias de resistência, esperanças de construir espaços para o livre pensar e iniciativas de transformações sociais e políticas que redundaram em dinâmicos e complexos processos de implementação em diferentes campos sociais.

Especificamente no campo da saúde mental estas memórias se caracterizam pela diversidade de atores, intencionalidades e influências. A Reforma Sanitária, iniciada em meados dos anos setenta, justifica essa afirmação. Dela participaram estudantes, intelectuais e profissionais de várias áreas, além de protagonistas de movimentos sociais organizados ou não que, em seus reclamos cotidianos, bradavam por relações mais universais e igualitárias nas práticas sociais vinculadas à saúde (BRASIL. MINISTÉRIO DA SAÚDE, 2006).

Nessa perspectiva, narrativas desse período revelaram espaços de experiência potencialmente fortes para a transformação dos horizontes de expectativas (KOSELLECK, 2006) e dos fazeres destinados aos problemas de saúde da população. Ao mesmo tempo, incrementaram discussões e transformaram conceitos. É o caso da instituição do Sistema de Saúde Comunitária São José do Murialdo, no Rio Grande do Sul, no qual tentativas de ampliar espaços de participação, associadas à proximidade cotidiana entre as pessoas, direcionavam práticas diferenciadas e formulavam interrogações sobre lugares instituídos para saberes e ações.

Contrapondo algumas memórias coletadas acerca dessa experiência, naquela época era evidente a hegemonia de um modelo biomédico para as práticas de saúde. Este demandava fazeres pautados pela linearidade e pelos antagonismos que fragmentam os sujeitos e suas possibilidades de vida: individual-coletivo, normal-patológico, saudável doente, perigoso-inofensivo e, por último dentro-fora do manicômio ou das prisões. Nessa lógica, diagnósticos psiquiátricos, rigorosa prescrição medicamentosa e internações por longos períodos abarrotavam os manicômios e normatizavam comportamentos.

Estas circunstâncias de padronização e repressão eram coniventes com as condições políticas do contexto brasileiro da época. A vigência do golpe civil-militar que cerceou a liberdade política naquele período e que, ainda hoje, marca as relações sociais brasileiras (HERNANDEZ; SCARPARO, 2007) tinha nas propostas de padronização e controle dos comportamentos um forte aliado. Ao mesmo tempo, o cenário 
mundial delineava contextos caracterizados por movimentos coletivos que questionavam as hegemonias e tensionavam posições de poder e verdades absolutas. É o caso do maio francês, das manifestações feministas e do movimento anti-racista, entre outros.

Desse modo, as circunstâncias de construção das práticas relativas à saúde mental naquele período, no contexto brasileiro, assumiram a característica de constante gestação e mudança. Elas narram processos de transformações de práticas e concepções que evidenciam as articulações locais e globais na construção de outros lugares sociais. No caso dos portadores de sofrimento mental destaca-se o Movimento da Luta Antimanicomial.

Em pesquisa desenvolvida acerca dos processos relativos a esse movimento no Rio Grande do Sul (SCARPARO, 2005), mostra-se relevante a ação de mulheres para as conquistas efetivadas. Estudantes e profissionais, especialmente vinculadas à área da psicologia, formularam projetos profissionais, organizaram-se e empreenderam esforços em diferentes âmbitos para que os propósitos de articulação entre trabalho em saúde mental e cidadania tivessem êxito. Como decorrência inseriram-se nos movimentos estudantis, em práticas de formação e intervenções profissionais que contemplassem o desejo de interferir nas políticas de saúde e, prioritariamente, na formulação de estratégias de intervenção psicossocial nesse campo. Assim, os profissionais de psicologia passaram a compor equipes multidisciplinares nos cuidados e atenção à saúde, marcando seu potencial de ação transversal nas práticas sociais e institucionais, contribuindo na invenção dos diferentes modos de afirmar a vida (FAGUNDES, 2004). Desta forma, torna-se relevante discutir as articulações e interfaces estabelecidas entre a psicologia e a organização das práticas em saúde mental, principalmente quanto às práticas, intervenções e formação desta área para atuar nas Políticas Públicas de Saúde Mental que começavam a desenhar-se no panorama da Reforma Psiquiátrica.

Para relatar estudos sobre estas questões construímos o texto que segue. Primeiramente registramos e justificamos a escolha metodológica utilizada para os procedimentos de coleta e análise dos dados, tendo em vista na perspectiva da História Oral. Em seguida descrevemos aspectos do contexto sócio político do Brasil nos anos sessenta, setenta e oitenta. Logo após associamos a essa descrição contextual memórias acerca das transformações no campo da saúde mental, a partir de inserções em espaços de experiências voltados para as políticas do existir desde o período de formação acadêmica. Finalmente tecemos algumas considerações acerca das relações entre essas memórias e a inserção da psicologia nas políticas públicas de saúde mental.

\section{Procedimentos metodológicos}


A opção prioritária pela perspectiva da história oral ocorreu pela convicção de que esta abordagem transcende a noção de técnica por sua abrangência e complexidade (FERREIRA; AMADO, 2006). Trabalhar com esta perspectiva de pesquisa favorece possibilidades de reconstrução do objeto de estudo através das memórias dos participantes, o que transforma a investigação em um processo dialógico a priori.

Para a coleta e análise das entrevistas utilizamos como recurso a Entrevista-narrativa (JOVCHELOVITCH; BAUER, 2002). Trata-se de um procedimento qualitativo que utiliza colóquios não estruturados a fim de preservar a fluidez do discurso. Além da escolha dos participantes, cuidou-se também do contexto da narrativa e do registro detalhado do seu conteúdo. Também preencheu-se, a cada entrevista, um quadro de análise dos dados e organização dos conteúdos das narrativas. Tal quadro apresentava os seguintes ítens:

1. Textos indexados: referências formais a profissionais, bibliografias, documentos e instituições;

2. Textos não-indexados: valores, juízos, conhecimento do senso comum, opiniões e sugestões;

3. Análise da trajetória: modos de organização das experiências.

4. Análise do conhecimento: os textos não-indexados são utilizados para evidenciar modos não convencionais de operar sobre o objeto de estudo;

5. Identificação de continuidades ou rupturas com os processos em andamento no contexto estudado

Logo após realizou-se a fusão dos horizontes hermenêuticos (Bauer, 1996) nos quais se estabeleceram interlocuções entre os materiais analisados, os conceitos estudados e as considerações quanto ao processo de investigação vivido. Constituiu-se assim, síntese integradora entre os resultados teóricos e empíricos, o que possibilutou espaços para as considerações críticas e reflexivas sobre o tema. Alguns resultados desse processo apresentaremos a seguir.

\section{O Brasil da Repressão e da construção da Psicologia como Profissão}

Estudos acerca das circunstâncias histórico-políticas do Brasil a partir dos anos sessenta fornecem pistas para pensar as trajetórias de inserção da psicologia no campo das políticas de saúde mental no Brasil. A década de sessenta tem sido descrita como um conturbado período político-social. Os sete meses de governo de Janio Quadros e os trinta de Goulart registram disputas, estratégias de oposição e tensionamentos. No meio intelectual proliferavam discussões norteadas pelo nacionalismo e pelo desenvolvimentismo. Num contexto político-social assim sobressaltado, a instauração da ditadura civil-militar foi mais um evento, se prolongou oficialmente 
por mais de duas décadas e até hoje evidencia suas marcas (MACHADO; SCARPARO, 2010)

A Psicologia recentemente havia sido oficializada como profissão, através da lei 4119 de 27 de agosto de 1962. Após a euforia por esse reconhecimento, iniciaram-se movimentos pela delimitação e defesa das fronteiras profissionais. Dentre os resultados de uma pesquisa desenvolvida sobre as representações da psicologia nesse período (SCARPARO; MAYER, 2010) ${ }^{1}$, foi comum a associação da profissão a métodos de ensino e treinamento nos campos educacional e do trabalho. Por isso, ao usar como fonte os jornais da época, encontramos majoritariamente matérias acerca de atividades provenientes de exames psicotécnicos - como divulgação de cursos sobre testes e resultados de processos seletivos. Outras matérias descreviam a importância do conhecimento de psicologia para o sucesso nas vendas e outras, ainda, abordavam estratégias educacionais na família e comportamentos considerados adequados para a juventude. Essas últimas ressaltavam o aspecto preventivoevitativo dos saberes disponibilizadas pela área. Podemos citar como exemplo as matérias intituladas "Por que meu filho desobedece?" (ROESCH DA SILVA, 1962) ou "Como descobrir precocemente a tendência para o crime?" (REIS, 1962) e “De transviado a delinquente vai apenas um passo". Também neste ano apareceram outras manchetes que relacionavam acontecimentos da época às práticas psicológicas, seja pára explicá-las ou para indicar a psicologia como ferramenta de evitação de conflitos. A vigência da Guerra Fria associada ao temor de mais uma Guerra Mundial, por exemplo, associou o saber psicológico à prevenção de conflitos internacionais. É o que revela a manchete: "Psicologia acumula dados que podem ser usados para prevenir Guerras". Além disso, a dimensão de instrumento para aconselhamento individual emerge na matéria e "Porque escrevemos o livro "Conselhos a um Nervoso" (TEIXEIRA, 1962). Ao mesmo tempo, matérias sobre manifestações psicopatológicas em público corroboravam a associação de loucura a perigos eminentes. É o caso da reportagem "Triste recorde para o Brasil: o da loucura". (CORREIO DO POVO, 1962) Esses são exemplos das expectativas para a psicologia na época e para seu campo de atuação: a avaliação psicológica e psicotécnica, pautadas na idéia de normalidade e práticas de prevenção de crises e conflitos, tendo como meta e idéia de saúde mental, relações consensuais e harmônicas (SCARPARO; MAYER, 2010).

Em 1964, instaurou-se a ditadura civil-militar no Brasil. Os registros acerca do contexto brasileiro desta época narram episódios de repressão da vida civil e intervenções radicais no cotidiano das instituições dos movimentos sociais e da população em geral (GALEANO, 2000; SCARPARO, 2005). Tratou-se de um fenômeno geo-político uma vez que muitos países da América Latina também 
viveram essa condição política. Ciência, tecnologia e informação eram categorias pertencentes à Segurança Nacional, o que teve como decorrência a intensificação do seu controle pelo Estado (SANTOS, 1999). Os intelectuais eram tidos como potencialmente perigosos e frequentemente eram perseguidos politicamente. Além disso, fazia parte dos planos do governo ditatorial a importação de tecnologias o que se traduzia na articulação de projetos políticos, industriais e de desenvolvimento da nação aos interesses estadunidenses (MARTINS, 2004). Dentre os episódios relacionados a essas articulações encontram-se projetos de investigações psicológicas subsidiados pela Fundação Ford. É o caso de uma pesquisa sobre as motivações e comportamentos dos prefeitos eleitos em 1968, por exemplo (SALDANHA, 1974).

Como ilustram os exemplos, os discursos sobre as idéias e saberes psicológicos poderiam ser usados no sentido de legitimar mecanismos sociais da desigualdade e da opressão (SCARPARO, 2005). Tal constatação foi um dos motes da "crise de relevância da psicologia social" que expressava a inconformidade de profissionais da área com práticas pautadas pelo individualismo e pela neutralidade, negando as especificidades históricas, sociais, políticas e culturais dos contextos de inserção (BERNARDES, 1998; SCARPARO; GUARESCHI, 2007). Associadas a esses questionamentos encontram-se as perspectivas de discussão de um movimento mundial no âmbito das políticas de saúde, na segunda metade da década de setenta. Tal movimento lutava pela ampliação da assistência em saúde e equidade no atendimento. Dentre os eventos importantes desse movimento está a Conferência de AlmaAta, em 1978 (SCARPARO, 2002).

As pressões sociais infringidas pela ditadura começaram a dar sinais de enfraquecimento em meados dos anos setenta e o processo de abertura política no Brasil, foi marcado por incontáveis mobilizações coletivas. Queremos destacar aqui o "Movimento da Reforma Sanitária", pois deu vazão a intensificação das articulações entre saúde, políticas sociais e práticas psicológicas. Esse Movimento foi protagonizado por trabalhadores dedicados à área, além de contar com a participação de universitários e de outros segmentos da sociedade. A Reforma pretendia a construção de uma Política de Saúde democrática, descentralizada, universal e unificada. As práticas desenvolvidas até então estavam alicerçadas no discurso do atendimento centrado nos médicos e nos hospitais, numa lógica linear, como foi dito acima, o que não contribuía com a melhoria das condições de saúde das populações. Ao contrário, ao se filiar à lógica "problema-solução" estabeleciam relações de dependência, desconsiderando ou hierarquizando diferenças e negando as possibilidades de participação na construção das práticas, no campo da saúde. A crítica ao asilo deixa de visar seu aperfeiçoamento ou humanização, vindo a incidir sobre os próprios pressupostos da psiquiatria, a condenação de seus efeitos de normatização e controle 
(TENÓRIO, 2002). As propostas iniciais de ação vieram com o Programa de Interiorização das Ações de Saúde e Saneamento - PIASS, em 1976; depois com o Programa Nacional de Serviços Básicos de Saúde - PREVSAÚDE, em 1980; após, em 1982, com a Política de Ações Integradas de Saúde - AIS. (MALIK, 1998).

Nesse período, apesar da manutenção de restrições aos movimentos sociais transpareciam críticas ao sistema vigente em propostas de ruptura com o chamado "assistencialismo" exercido por atividades filantrópicas e empresariais. A contingência da ditadura não tornava convidativa a cooperação com o governo. De qualquer forma, evidenciavam-se movimentos sociais e lutas pelos direitos das minorias, tendo importante papel na valorização dos espaços para discussão das políticas públicas.

Os avanços da Reforma aconteciam em meio a ambigüidades no processo de enfraquecimento do Estado de Segurança Nacional traduzidos pela possibilidade de expansão de movimentos populares contrapostos pela implementação de uma lei de anistia resultante de "evidente acordo entre as pressões oposicionistas e as preferências dos setores militares de linha dura" (ALVES, 2005, p. 321).

A realização de Conferências de Saúde abriu espaços para debates e formulação de propostas concomitantes a significativas transformações nas concepções de saúde. Em 1986 teve lugar a VIII Conferência Nacional de Saúde. Neste momento foram explicitados os princípios da Reforma Sanitária e, em 1987, foi instituído o Sistema Unificado e Descentralizado de Saúde - SUDS - a composição de ações Integradas baseadas na universalização e a eqüidade no acesso, na integralidade do cuidado, na regionalização dos serviços, na implementação de distritos sanitários; na descentralização, no desenvolvimento de instituições colegiadas gestoras e de políticas de recursos humanos (MALIK, 1998). Essas práticas aparecem articuladas ao movimento constituinte, voltado para a promulgação de uma constituição que garantisse, no texto legal, um meio ambiente saudável, controle social, descentralização e integralidade.

Em 1988, em um clima de euforia democrática, foi promulgada a nova Constituição brasileira. Esta propiciou a criação e legitimação de um Sistema Único de Saúde que potencializou a emergência de sujeitos políticos (MEDEIROS et al., 2005) com propostas de atenção integral e participativa. Assim, o sujeito é considerado cidadão e, portanto, produz e é produzido recursivamente o entorno de inserção.

Muito antes da aprovação da Lei da Saúde Mental, sete estados e o Distrito Federal já haviam aprovado leis que previam que gradativamente a assistência em hospital psiquiátrico de internação fosse substituída pelo tratamento em outros dispositivos e serviços. O caminho percorrido pelo Ministério da Saúde incluiu a edição de onze portarias que, em seu conjunto, constituíram um marco normativo significativo, tanto para o controle dos hospitais psiquiátricos em 
funcionamento no país, quanto para o incentivo à criação de dispositivos de novo tipo (TENÓRIO, 2002).

Apenas em seis de abril de 2001, o Presidente da República sancionou a Lei de Saúde Mental (Lei 10.216). A aprovação da lei aconteceu depois de decorridos 12 anos da apresentação, pelo deputado Paulo Delgado, do projeto de lei original. Nesses anos, o texto de Delgado sofreu inúmeras mudanças que acabaram amenizando seu tom marcadamente reformista, mas que produziram, assim mesmo, uma lei considerada progressista (TENÓRIO, 2002). Mesmo sem o impacto que o texto original prometia, pensamos que essa lei representa uma conquista, e pode ser significada como um dispositivo para transformação dos serviços oferrecidos ao portador de sofrimento psíquico no Brasil. De acordo com Tenório (2002), o maior obstáculo à reforma, ainda hoje, é o crescimento desordenado da oferta de internações psiquiátricas gratuitas, sobretudo pelo setor contratado, à medida que elas cristalizam um sistema manicomial.

No decorrer desse processo têm sido geradas estratégias de inserção para atender às perspectivas e orientações explicitadas formalmente pelas políticas governamentais. No campo da saúde mental destacamse as propostas decorrentes do movimento da luta antimanicomial e das políticas de humanização que redundaram na formulação de espaços emancipatórios como esteio para as intervenções. Essas perspectivas supõem intensas e dinâmicas redes de relações, o que implica contínua interlocução e solidariedade nos diferentes momentos e cenários de trabalho.

No que se refere às especificidades das práticas de saúde mental no Rio Grande do Sul destacam-se processos de formulação e implementação de políticas voltadas para a integralidade e controle social mesmo antes da consolidação do SUS, motivo pelo qual, descrevemos, abaixo, duas dessas experiências.

\section{Experiência precursora no campo da saúde mental - o Centro Médico Social São J osé do Murialdo}

A saúde mental tem se constituído num campo promissor para o desenvolvimento de práticas de psicologia e, em especial, de psicologia social no Brasil. Tornou-se simultaneamente espaço de intervenção para as práticas psicológicas e um lugar de explicitação e experimentação das diferenças, possibilidades e limites da profissão. Por exemplo, na década de setenta intensificaram-se processos de inclusão de fazeres psicológicos nas comunidades, através da associação a projetos de atenção à saúde. O exame de documentos sobre as circunstancias das práticas de saúde nesse período evidenciou a influência dos Seminários de Medicina Preventiva e Social, realizados em 1955 e 1956 e patrocinados pela Organização Pan-Americana de Saúde (OPAS). Nas discussões propostas nesses eventos sobressaiu-se a necessidade de integração bio-psico-social que se tornou forte 
indicação para inspirar a formação e as práticas em saúde (GARCIA, 1981).

A maioria das perspectivas de saúde da época seguia os preceitos da medicina clássica, ou seja, era pautada nas díades médico-paciente e problema-solução. A ênfase na prevenção intensificada após a Segunda Guerra Mundial aproximou muitos fazeres das indicações da Psiquiatria Comunitária, um ramo da Psiquiatria Social centrado nos fatores etiológicos da doença mental, articulados aos modos de vida das famílias nas comunidades, tendo em vista os processos de adaptação dos indivíduos às circunstancias sociais e culturais (Busnello, 1976; COWEN; LORION, 1975). Desse modo, mantinha-se a cisão indivíduosociedade presente nas propostas de Psicologia Social que, na época, eram importadas predominantemente dos Estados Unidos para as academias brasileiras (SCARPARO, 2003).

Em pesquisa realizada acerca das memórias de profissionais da saúde é curiosa a imediata associação da escolha desta abordagem ao momento político vivido pelo País. A psiquiatria Comunitária foi reconhecida como um instrumento de difusão de ideologias e de dominação na medida em que, nos anos 60 e 70, havia a tutela estadunidense para a implementação e desenvolvimento de trabalhos de saúde comunitária no Brasil. Por exemplo, equipes brasileiras recebiam assessoria em saúde de técnicos estadunidenses. É o caso do Hospital de Clínicas e do Centro Médico Social São José do Murialdo (CMSSJM), em Porto Alegre. Além disso, os aparatos teórico-técnicos indicados pela Psiquiatria Comunitária eram justificativas consideradas pertinentes para viagens de estudo aos EUA e à Inglaterra com vistas à formação de profissionais para trabalhar no campo da saúde brasileira (SCARPARO, 2005).

Ao mesmo tempo, havia inquietações e tensionamentos que denunciavam a predominância de técnicas individuais e práticas elitistas, além da ênfase na idéia de cura e na prevenção secundária. Questionava-se, ainda, o emprego excessivo de psicofármacos e a dissociação entre a manifestação da doença e o contexto político-social no qual se instituía a enfermidade. Tais questionamentos eram intensificados pelo ideário de diversos movimentos sociais que caracterizavam a época e se pautavam na critica aos modos de vida/valores predominantes da época. Podemos citar como exemplos, o movimento feminista, anti-racista e estudantil, entre outros. Especificamente no campo da saúde mental, destaca-se o movimento da Antipsiquiatria. Este se contrapunha à constituição de espaços de poder nas relações estabelecidas na psiquiatria clássica e contestava radicalmente os saberes e as práticas psiquiátricas vigentes e buscando transformar os tratamentos manicomiais (ROUDINESCO; PLON, 1998). Ao contrário da Antipsiquiatria, cujos expoentes tinham suas publicações proibidas no período do Golpe de 64, a Psiquiatria Comunitária parece ter sido bem aceita pelo governo ditatorial da 
época e serviu de apoio a programas preventivos na área da saúde no Brasil, uma vez que seu processo de implementação não propunha nenhum rompimento direto nem com as políticas de saúde, nem com as políticas sociais vigentes.

No Rio Grande do Sul instituiu-se o trabalho na Vila São José do Murialdo. Este se desenvolvia na esfera pública e se destinava à redução da incidência e da prevalência do adoecimento da população como um todo. Ao contrário do que indicava a medicina clássica, não deveria haver, neste caso, a consideração de episódios isolados de adoecimento; ou seja, os objetivos a alcançar dirigiam-se à comunidade e não somente a alguns indivíduos. Como decorrência, houve necessidade de reorganização dos serviços oferecidos à população (BUSNELLO, 1972; 1976; 1981). Tal reorganização resultou na construção de um sistema de saúde comunitária que, entre outras inovações, instituiu a primeira residência multiprofissional do Brasil e cunhou uma nova tipologia médica: a do médico geral comunitário (SCARPARO, 2005).

A experiência do Centro Médico Social São José do Murialdo (CMSSJM) é considerada por muitos como precursora de práticas de saúde coletiva e, especialmente, de saúde mental no Brasil. Nessa experiência a comunidade foi o espaço que favoreceu a consolidação da inserção da psicologia em equipes de trabalho no âmbito da saúde pública, o que, de certa forma, ampliava os espaços de compreensão e intervenção da psicologia neste campo. As práticas de saúde mental, então, deveriam ser cotidianamente integradas ao trabalho da equipe, no atendimento à saúde da comunidade (BUSNELLO; ZIMERMAN 1973). .

É curioso observar que, apesar da criação do CMSSJM coincidir com a vigência da ditadura no Brasil, isso não impediu sua instituição. Pelo contrário, parece ter sido estimulado pelo governo. Além disso, contava com a participação de profissionais de várias áreas e diversas tendências políticas. Talvez por isso, tenha sido também considerado "nicho de acomodação" para controle de dissidências ao governo ditatorial (SCARPARO, 2005). As narrativas mostram que essa experiência foi fundamental no sentido de favorecer o engajamento de trabalhadores de saúde mental em processos sociais, especialmente o movimento da luta antimanicomial nos anos oitenta. Tal engajamento favoreceu a criação de serviços e o fortalecimento da proposta da reforma psiquiátrica no Estado, aprovada alguns anos depois.

Scarparo (2002) relata que Ellis Busnello, um dos idealizadores um dos idealizadores do projeto $^{2}$, afirmou em entrevista não ter presenciado outro momento no qual se efetivassem tantas mudanças de atitudes e comportamentos. Considerou que a equipe do Murialdo, a partir desta prática, antecipou-se à Conferência de Alma Ata, tendo efetivado cinco anos antes deste evento, muitas práticas que a Conferência viria a indicar. Para ele, a emergência da psiquiatria comunitária associada às inquietações atinentes à psiquiatria clássica promoveu movimentos de 
transformação nas práticas em saúde mental. No seu caso, teve acesso aos aportes da Psiquiatria Comunitária nos anos sessenta, quando trabalhava no Hospital Psiquiátrico São Pedro e experimentava inconformidades com as práticas de atendimento nas instituições psiquiátricas. Em função disso realizou viagens de estudos para a Inglaterra e os Estados Unidos onde aprofundou seus conhecimentos sobre Psiquiatria Comunitária. No seu retorno, apoiado por Paulo Guedes, então diretor do Hospital psiquiátrico São Pedro, Busnello e uma equipe de profissionais empenharam-se na implantação de um Sistema de Saúde Comunitária no espaço destinado a uma experiência pré-existente, resultante de um convênio entre o Estado e a Universidade do Rio Grande do Sul (URGS) para prestar serviços médicos à comunidade abrindo campo de estágio e formação em serviço. Assim, houve a saída do Hospital Psiquiátrico para a comunidade na tentativa de estabelecer mudanças nos processos de atendimento à população. Com esta mudança as práticas de atendimento psiquiátrico confinadas no hospital, passaram a configurar-se na criação de estratégias de atenção à saúde como um todo.

Os anais da VI Conferência Pan-americana de Educação Médica e XIV Congresso Brasileiro de Educação Médica (FEDERAÇÃO PANAMERICANA DE ASSOCIAÇÕES DE FACULDADES DE MEDICINA; ASSOCIAÇÃO BRASILEIRA DE EDUCAÇÃO MÉDICA, 1976), contém o relato de integrantes dessa equipe sobre a experiência. Foi unânime a idéia de que o deslocamento do Hospital Psiquiátrico para a comunidade rompeu com as práticas fragmentadas da medicina clássica e desdobrou-se nas transformações subseqüentes. Além disso, afirmaram que, provavelmente, o CMSSJM tenha sido a primeira experiência desse tipo no Brasil (AVERBUCK et al., 1976).

O processo de elaboração do "Projeto de um Sistema Comunitário de Saúde" aconteceu de outubro de 1974 a abril de 1975 e ancorava-se nos conceitos formulados pela Organização Mundial da Saúde (OMS), que recomendava a integração entre físico, mental e social. Assim, indícios de integralidade, princípio mais tarde adotado pelo Sistema único de Saúde brasileiro (SUS), era diretriz do serviço e a sua avaliação teria como critério os índices de resolução e não estatísticas sobre processos de adoecimento.

Nesse período, ainda marcado pelo contexto do Golpe de 1964, era comum ter, como estratégia de divulgação ideológica, projetos governamentais assessorados tecnicamente por profissionais estadunidenses. Foi o caso da implantação do CMSSJM, no qual a psicóloga Patrícia Bradley, beneficiária de uma bolsa de estudos, contribuiu com aportes da Psicologia Organizacional para o planejamento e estruturação do referido centro. $O$ exame das narrativas dos integrantes daquela equipe evidencia que, para alguns, essa experiência foi exemplo das interferências dos EUA "que 
intervinham no campo da saúde pública, em países do Terceiro Mundo" favorecendo o a difusão de teorias e visões do "american way of life". A equipe adotou, ainda, conteúdos de medicina comunitária inglesa, utilizados pela Escola de Saúde Pública da Johns Hopkins University. Nas narrativas coletadas sobre as memórias desse processo, o livro "Health by the people" foi mencionado frequentemente. Tratava-se de uma obra utilizada pela OMS (NEWELL, 1975) para apoiar suas propostas e linhas de atuação. Foram apontados também conhecimentos advindos das experiências de saúde comunitária cubana e da psiquiatria de setor francesa.

O trabalho supunha a setorização da comunidade em quatro subáreas que eram atendidas por equipes de cuidados primários (AVERBUCK, et al. 1976; BUSNELLO et al., 1975). Integravam a equipe um médicogeral, auxiliares e voluntários de saúde que tinham como objetivo transformar atribuições convencionais para práticas na saúde em práticas na atenção primária, fortemente inspirados nos modelos anglosaxões de medicina comunitária. O quadro abaixo, elaborado tendo por base as publicações da equipe na época, ilustra o esforço da mesma em promover mudanças de perspectiva de processo de trabalho em saúde, em direção à atenção primária.

Funções clássicas dos sistemas de saúde e em nível de cuidados primários: 


\begin{tabular}{|c|c|}
\hline Modelo convencional & Atenção primária \\
\hline $\begin{array}{l}\text { O primeiro contato do usuário com o serviq de } \\
\text { saúde acontece, necessariamente, pela demanda do } \\
\text { paciente }\end{array}$ & $\begin{array}{l}\text { Primeiro contato com o usuário do Sistema de } \\
\text { Saúde pode ocorrer por procura espontânea ou } \\
\text { rastreamento }\end{array}$ \\
\hline $\begin{array}{l}\text { Interesse geral e atendimento baseado em critérios } \\
\text { procedimentos uniformes }\end{array}$ & Interesse personalizado e permanente \\
\hline $\begin{array}{l}\text { Voltado para os episódios de adoecimento de } \\
\text { individuos }\end{array}$ & $\begin{array}{l}\text { Voltado para as necessidades integrais dos } \\
\text { moradores }\end{array}$ \\
\hline Diagnóstico e prognóstico individual & $\begin{array}{l}\text { Identificação de problemas físicos, mentais e } \\
\text { sodais na comunidade }\end{array}$ \\
\hline Encominhamentos para serviqs espedalizados & $\begin{array}{l}\text { Exacuço direta da maior parte dos serviqs de } \\
\text { saúde necessários }\end{array}$ \\
\hline Atendimento à demanda por servigs especializados & $\begin{array}{l}\text { Encominhamento, controle e coordenạ̧o dos } \\
\text { servigs especializados que se fizerem } \\
\text { necessários. }\end{array}$ \\
\hline $\begin{array}{l}\text { Aten ção exdusiva aos casos que impliquem uso do } \\
\text { serviços de saúde disponiveis }\end{array}$ & $\begin{array}{l}\text { Colaboração para a solução de problemas que } \\
\text { dependam de ações externas ao sistema de } \\
\text { saúde }\end{array}$ \\
\hline $\begin{array}{l}\text { Avaliaçôo dos resultados do trabalho através da } \\
\text { índices de es de cura dos casos individua } \\
\text { atendidos }\end{array}$ & $\begin{array}{l}\text { Awaliaça com a comunidade dos resultados dq } \\
\text { serviqs recebidos e planejamento conjunto da } \\
\text { atividades de saúde }\end{array}$ \\
\hline $\begin{array}{l}\text { Enfase em medicamentos e técricas que favoreçn } \\
\text { a cura das doenças dos individuos }\end{array}$ & $\begin{array}{l}\text { Enfase em atividades que visem a manutença } \\
\text { da saúde }\end{array}$ \\
\hline $\begin{array}{l}\text { Ter treinamentos individuais esporádicos em áreas } \\
\text { de especializạ̧o }\end{array}$ & $\begin{array}{l}\text { Execugão permanente de atividades } \\
\text { trenamento em serviço e de desenvolviment } \\
\text { organizadional }\end{array}$ \\
\hline $\begin{array}{l}\text { Realizậo de estudos e pesquisas para } \\
\text { determinar técnicas terapêuticas e medicamentos } \\
\text { mais eficientes }\end{array}$ & $\begin{array}{l}\text { Realizaçồ de estudos e pesquisas para } \\
\text { determinar prioridades e formas de organização } \\
\text { do trabalho }\end{array}$ \\
\hline
\end{tabular}

Quadro elaborado com base em Busnello et al. 1976 e Averbuck et al., 1976.

Os trabalhos desenvolvidos eram organizados como programas e tinham objetivos voltados para as necessidades de saúde bio-psícosocial da população. Além da assessoria multidisciplinar, as equipes distribuíam-se em três coordenações: a de serviços, a de administração e planejamento e a de ensino e pesquisa (AVERBUCK et al., 1976; BUSNELLO, et al., 1976) .

Em função do processo de ampliação das concepções de saúde, é relevante destacar que os profissionais pertencentes à equipe eram definidos como polivalentes, ou seja, deveriam estar aptos a realizar todo o tipo de tarefa, sem preocupar-se exclusivamente com a especificidade de sua formação. Assim, a expressão "curinga do baralho" era utilizada para designar a amplitude das atribuições dos 
integrantes da equipe (BUSNELLO; LEWIN; RUSCHEL; BRADLEY, 1975).

Ao avaliar a experiência, Busnello considerou evidente a intencionalidade de rompimento com relações verticais entre profissionais e a população. Nessa perspectiva, ressaltou posturas que, muitas vezes "escandalizavam alguns membros da equipe". Citou como exemplo, a consideração do trabalho realizado pelos curandeiros da região e a posição "polêmica e divertida" na época de que a organização e os critérios de atendimento deveriam ser definidos em conjunto, com a participação da comunidade. Para disseminar essa forma de trabalho em saúde pública, foi produzido um amplo material, que enfocava as definições de cuidados primários, famílias de risco e espaços de domínio de todos os integrantes da equipe (BUSNELLO, 1976). Tais modos de vislumbrar as práticas de saúde impunham a formalização de uma nova especialidade médica: a de médico geral comunitário. Depois de um longo processo e o registro dessa tipologia junto à Comissão Nacional de Residência Médica do Ministério da Educação, tornou-se possível propor e instituir uma residência voltada para esse campo. Associada a ele surgia a polêmica idéia de uma proposta multiprofissional na qual saberes de várias áreas poderiam interagir igualitariamente na prática de cuidado da saúde da população.

Busnello lembrou que alguns membros da equipe, especialmente da área médica, não aceitavam essa inovação manifestando seus receios de que a flexibilização de fronteiras disciplinares pudesse prejudicar o andamento do trabalho. Entretanto, a idéia de que essa proposta deveria ser experimentada, venceu e, a partir de então, houve colaboração da equipe na consecução da residência.

No parecer do Ministério da Saúde e da Educação sobre a proposta, consta que o termo "residência" era específico da área médica e que no Brasil, não havia residência para outros profissionais. Abriu-se, então, a perspectiva de fazer um curso de especialização para nãomédicos, paralelo e igual à residência médica. Esses estavam vinculados à Diretoria de Ensino do CMSSJM. Essa Diretoria também organizava cursos para voluntários e outros cursos para a população em geral e trabalhava no sentido de possibilitar o intercâmbio de professores. Assim, Ao concluir a residência, os/as médicos/as recebiam um Certificado da Comissão Nacional de Residência Médica. Os demais profissionais recebiam o certificado de Especialista em Medicina Comunitária, fornecido pela Escola de Saúde Pública do Estado.

Em 1976, inaugurou-se esta formação em serviço sob a coordenação do médico Carlos Grossmann. Tinha a duração de dois anos e o envolvimento dos integrantes da equipe nesse projeto fortaleceu a convicção da necessidade de formar profissionais polivalentes. A idéia atraiu representantes de diferentes especialidades. Dentre esses 
predominavam médicos, enfermeiros, odontólogos, psicólogos e assistentes sociais. Foram citados também terapeutas ocupacionais, administradores de empresas, sociólogos e veterinários. No decorrer da experiência a proximidade com o contexto das classes populares e a prática de atendimento "na beira das casas" provocou mudanças quanto aos significados dos conceitos e das práticas e à responsabilidade social do trabalho no campo da saúde. Na medida em que transcorria a experiência viviam-se rotinas e hábitos completamente diferentes daqueles presentes no atendimento hospitalar.

Alguns dos participantes da pesquisa lembraram que os estudantes ficavam desconfortáveis em contatar com as circunstancias da pobreza extrema. Busnelo, por exemplo, ponderou que na época, o Brasil crescia a 3,2\%, o índice de natalidade era descontrolado e predominavam as doenças infecciosas e parasitárias o que se agravava com a falta de esgotos e saneamento nas comunidades. Ressaltou, que o estranhamento atribuído aos estudantes também o acompanhava e que, mesmo sendo psiquiatra e psicanalista, se viu obrigado a assumir o lugar do profissional polivalente e aprender questões acerca das necessidades urgentes da população. Aprendeu, por exemplo, como se armava uma latrina, qual a maneira correta de armazenar água, como se faz a higiene de uma casa e como tratar escabioses.

Os estudantes visitavam a comunidade e conheciam os diferentes contextos de vida cotidiana da região. No decorrer desse processo participavam de discussões, supervisões e treinamentos. Ao mesmo tempo, realizavam visitas domiciliares como apoio ao trabalho comunitário. Em seguida, dedicavam-se ao atendimento de uma família facilitando a mobilidade das pessoas para a utilização dos recursos de saúde disponíveis. Entretanto, em algumas das narrativas coletadas aparece a idéia de que essa "prática comunitária" não era efetivada pelos profissionais que trabalhavam no projeto, o que provocava uma "curiosa dissociação". A academia apontava para um ideal que não se efetivava na ação dos preceptores. Tal situação provocava polêmicas e questionamentos quanto aos modos de gerenciar a formação em serviço oferecida naquele local. Da mesma forma, outros estranhamentos, por parte dos estudantes provocavam divergências. É o caso das propostas (inusitadas para a época) de planejamento familiar, das linhas teóricas adotadas, de manejos e posturas no campo de trabalho.

A convivência de profissionais e estudantes e a diversidade que caracterizava cada experiência e visão de mundo geraram a construção de espaços, até então, inusitados. As narrativas dos protagonistas desta história são carregadas de experiências, no mínimo, controvertidas. Por se tratar de um período de repressão política algumas atividades eram oficiais e expostas, outras, por 
iniciativa dos estudantes, eram clandestinas Por exemplo, ao mesmo tempo em que se estudavam intervenções pautadas na redução de índices epidemiológicos e possibilidades de adaptação ao ambiente, inspiradas nas idéias da Psiquiatria Comunitária (CAPLAN, 1980), se promovia, clandestinamente grupos de estudos sobre o pensamento de Paulo Freire, Marx e se recebia o argentino Alfredo Moffat, perseguido politicamente na Argentina. Por outro lado, ao mesmo tempo em que a experiência congregava profissionais e estudantes vinculados a diferentes ideologias, alguns dos quais desejosos de transformar a situação política vivida no País, se arranjava um "nicho" de acomodação para os dissidentes do governo ditatorial (SCARPARO, 2005). Tal diversidade interferiu de forma decisiva nos projetos sociais, de vida e profissionais de seus participantes. Muitos deles, a partir desse trabalho construíram suas carreiras no campo das políticas públicas de saúde. Dentre as experiências protagonizadas por participantes dessa história encontra-se a participação ativa e incondicional no movimento da reforma sanitária, na idealização e implementação do SUS, no movimento da luta antimanicomial, em produção de pesquisas científicas e em outras práticas militantes resultantes desses acontecimentos.

Cabe destacar que o trabalho de saúde comunitária desenvolvido no CMSSJM se mantém e se desenvolve no presente. Isto se estabelece através da continuidade e ampliação do atendimento à população da região e dos processos de formação - com as disputadas residências multiprofissionais. Com base nessas atividades cotidianamente as equipes e população envolvida geram a formulação de estratégias contextualizadas para a efetivação de políticas públicas de saúde.

\section{Considerações}

Escrever acerca de saúde mental no Brasil, numa perspectiva histórica, implica em se dispor a conhecer e refletir criticamente sobre os contextos histórico-políticos. Estes marcam as fontes de análise do estudo pretendido.

São evidentes, por exemplo, as marcas do contexto da Guerra Fria nas atribuições da Psicologia presentes nos documentos examinados. Nessa perspectiva, podemos citar a efetivação de tarefas pautadas na lógica da neutralidade, com a prescrição de modelos para o comportamento considerado normal e a importação de saberes e práticas estadunidenses como apoio à construção de intervenções no Brasil.

A análise do conjunto das fontes coletadas nos auxiliou vislumbrar um tempo contraditório. Por um lado, especialmente depois de 64, pleno de repressão política e, por outro, repleto de desejos emancipatórios. Como decorrência, a vida naquele contexto era eivada pelo controle ditatorial e sustentada pela criação de estratégias que subvertessem a ordem ditatorial. Tais estratégias foram narradas nos depoimentos. Elas eram decorrentes de reflexões críticas sobre os contextos de 
produção da vida no trabalho e na produção de conhecimentos e circunstancias que pudessem transcender as fronteiras disciplinares rigidamente estabelecidas.

Ao mesmo tempo, é interessante observar que a experiência do CMSSJM aqui descrita brevemente anuncia movimentos diversos que vinham se constituindo no campo da saúde e que transformaram concepções e práticas nesse campo. A idéia de deslocamento presente nas narrativas coletadas é um exemplo deste processo. Ao mesmo tempo em que havia o desejo de aproximação da vida cotidiana das comunidades, era evidente a desacomodação dos saberes disponíveis nas práticas hospitalares ou na medicina tradicional. Deslocar a equipe do hospital para a um local de moradia das classes populares pode ter sido significado por alguns apenas uma mudança geográfica na qual os instrumentos e as práticas do saber acadêmico eram aplicados, sem considerar as mudanças decorrentes das diferenças do contexto hospitalar para o de uma vila das classes populares. Por outro lado, os depoimentos coletados denotam dilemas éticos, questionamentos teóricos, reflexões críticas sobre as práticas lá efetivadas, formulação de estratégias de enfrentamento do inusitado presente no cotidiano e, como decorrência, importantes mudanças epistemológicas. Dentre essas queremos destacar a integração das práticas de saúde mental à noção de saúde comunitária. $\mathrm{Na}$ medida em que se propunha a aproximação da vida cotidiana, a consideração da necessidade de fortalecer a atenção primária e a perspectiva bio-psico-social para estabelecer o trabalho é evidente a incorporação da saúde mental na esfera da saúde comunitária, evitando fragmentações nas concepções de saúde.

A controvérsia de posicionamentos teórico-metodológicos narrada e explicitada na convivência cotidiana é outro tema que merece destaque. Equipes de profissionais e residentes, colaboradores, curiosos, moradores e gestores estabeleciam dialógicas através da necessidade de inventar modos de intervir no campo da saúde. Tal iniciativa potencializou o que, mais tarde, se configurou na perspectiva da integralidade proposta na Lei do SUS.

Desse modo, pensamos ser relevante destacar a importância da consideração da história, de suas marcas e de seus silêncios para compreender e discutir os processos de instituição de lugares sociais e as práticas dela decorrentes. Especialmente no que se refere ao campo da saúde no Brasil, tal consideração amplia e aprofunda a compreensão do trabalho de implementação do SUS e da complexa e dinâmica rede que se articula nessa tarefa para desafiar convicções, limites disciplinares e saberes instituídos como tal.

\section{Referências Bibliográficas}

ALVES, M. M. (2005) Estado e oposição no Brasil (1964-1984). São Paulo: Edusc, 2005. 
AVERBUCK, C.; CRISTÓVÃO, P.; FREITAS, C.; GERCHMANN, S.; PRADO, L.; SILVA, A; THOMAZ, T. Um projeto de Serviço de Saúde Mental Comunitário: Centro Médico Social São José do Murialdo de Porto Alegre. In: VI Conferência Pan-Americana de Educação Médica e XIV Congresso Brasileiro de Educação Médica, Anais, 1976, p. 443460.

BERNARDES, J. História. In Jacques, Maria da Graça (Org.). Psicologia social contemporânea. Petrópolis Vozes, 1998, p. 19-35.

BRASIL. MINISTÉRIO DA SAÚDE. Secretaria de Gestão Estratégica e Participativa. A construção do SUS: histórias da reforma sanitária e do processo participativo/Ministério da Saúde, Secretaria de Gestão Estratégica e Participativa. - Brasília: Ministério da Saúde, 2006.

BUSNELLO, E. A Integração da Saúde Mental num Sistema de Saúde Comunitária. 1976. Tese (Livre docência em Medicina) Faculdade de Medicina. Universidade Federal do Rio Grande do Sul, Porto Alegre.

BUSNELLO, E.; PINTO, E.; GUEDES, F. de B.; I. ARAÚjO, J; ZIMERMANN, J; SILVA, M; MACHADO, S. Nota Sobre a Mobilização de Recursos Comunitários não Psiquiátricos Para um Programa de Saúde Mental. Seminário Sobre Normas e Procedimentos Para o Manejo do Paciente Psiquiátrico. Manuscrito não publicado, 1972.

BUSNELLO, E.; LEWIN, I.; RUSCHEL, S.; BRADLEY, P. Projeto de um Sistema Comunitário de Saúde. Porto Alegre, Centro Médico Social São José do Murialdo da Secretaria da Saúde do Rio Grande do Sul, 1975.

BUSNELLO, E.; ZIMERMAN, D. A Equipe do Serviço Psiquiátrico de Comunidade. Revista da AMRI GS, v. 17, n. 2, p. 131-136, 1973.

CAPLAN, G. Princípios de Psiquiatria Preventiva. Rio de Janeiro: Zahar, 1980.

CORREIO DO POVO. Triste recorde para o Brasil: o da loucura.Correio do Povo, Porto Alegre, 09 de janeiro, 1962, noticiário, p. 13.

COWEN, E. L.; LORION, R. P. Multiple Views of a School Mental Health Project: a Needed Focus in Community Programs. Community Mental Health, v. 11 n. 2, p. 203-207, 1975.

FAGUNDES, S. Psicologia e políticas públicas: experiências em saúde pública. In: In: NASCIMENTO, C. A. T.; LAZZAROTTO, G. R.; HOENISCH, J. C. D. (Orgs.). Psicologia e políticas públicas: experiências em saúde pública. Porto Alegre: CRPRS, p. 7-8, 2004.

FERREIRA, M.; AMADO, J. Usos e abusos da História Oral. Rio de Janeiro: Editora FGV, 2006.

Federação Pan-Americana de Associações de Faculdades (Escolas) de Medicina; Associação Brasileira de Educação Médica. Anais da VI Conferência Pan-americana de Educação Médica, XIV Congresso Brasileiro de Educação Médica, 1976 nov. p. 17-19; Rio de Janeiro. Rio de Janeiro: ABEM, 1976. 
GALEANO, E. As Veias Abertas da América Latina. Rio de Janeiro: Paz e Terra , 2000.

GARCIA, J. Historia de las Instituiciones de Investigación en Salud en America Latina. Educacion Medica y Salud, v. 15, n. 1, p. 71-88, 1981.

HERNANDEZ, A.; SCARPARO, H. Da força bruta à voz ativa: a conformação da Psicologia no RGS nas décadas da repressão política. Rio de Janeiro: Mnemosine, v. 3, p. 156-182, 2007.

J OVCHELOVITCH, S.; BAUER, M. Entrevista narrative. In: BAUER, M.; GASKEL, G. Pesquisa qualitativa com texto, imagem e som: um manual prático. [Trad. Pedrinho Guareschi]. Petrópolis, RJ: Vozes, 2002.

KOSELLECK, R. Futuro Passado: Contribuição à semântica dos tempos históricos. Rio de Janeiro: Contraponto. PUC-Rio, 2006.

MACHADO, P.; SCARPARO, H. Golpe civil-militar: a psicologia e o movimento estudantil do Rio Grande do Sul. Memorandum, v. 19, p. 225-238, FAFICH, UFMG, 2010.

MALIK, A. M. Gestão de Recursos Humanos (v. 9). São Paulo: Faculdade de Saúde Pública da Universidade de São Paulo, 1998.

MARTINS, E. O Contexto político e o discurso da ciência da informação no Brasil. Uma análise a partir do IBICT. Ci. Inf. Brasília, v. 33, n. 1, p. 91-100, jan/abril, 2004.

MEDEIROS, P. F.; BERNARDES, A. G.; GUARESCHI, N. O conceito de saúde e suas implicações nas práticas psicológicas. In: Psicologia teoria e pesquisa, v. 21, n. 3, p. 263-269, 2005.

NEWEL, K.W. La Salud por el Pueblo. Genebra: Organização Mundial da Saúde, 1975.

SALDANHA, A. M. (1974). Psicologia Social y Psicologia Aplicada a la Vida Social, en UFRGS Cadernos de Psicologia Aplicada, v. 2, n. 1, p. 15-28, 1974.

SANTOS, S. G. M. Estado, ciência e autonomia: da institucionalização à recuperação de Manguinhos. 1999. Dissertação (Mestrado em Filosofia e Ciências Sociais) - Instituto de Filosofia e Ciências Sociais, UFRJ.

SCARPARO, H. Psicologia Comunitária no Rio Grande do Sul: considerações a partir de um estudo realizado. In: JACQUES, W. et al. (Org.). Histórias e Memórias de Psicologia: trabalhos premiados no concurso comemorativo dos 40 anos de regulamentação da profissão de Psicólogo no Brasil. Porto Alegre, RS: CRPRS. p. 59-72, 2003.

SCARPARO, H. Psicologia Comunitária no Rio Grande do Sul. Porto Alegre: EDIPUCRS, 2005.

SCARPARO, H. Psicologia Comunitária no Rio Grande do Sul registros da construção de um saber-agir. 2002. 439f. Tese (Doutorado em Psicologia) - Programa de Pós-Graduação da Faculdade de Psicologia. PUCRS. 
SCARPARO, H.; GUARESCHI, N. Psicologia Social comunitária e formação profissional. Psicologia e Sociedade, Porto Alegre, n. 19, Edição Especial 1, p. 46-56, 2007.

SCARPARO, H.; MAYER, N. Oficialização da Psicologia no Brasil: a construção de conhecimentos e práticas em contexto. Anais do XI salão de I niciação Científica. PUCRS, 2010.

REIS, J. Como descobrir precocemente a tendência para o crime? Correio do Povo. Porto Alegre, 11 de novembro de 1962. Reportagem, p. 15- 16.

ROESCH DA SILVA. Por que meu filho desobedece? Correio do Povo. Porto Alegre, 18 de novembro de 1962. Sessão feminina, p. 25.

ROUDINESCO, E.; PLON, M. Dicionário de Psicanálise. Rio de J aneiro; J orge Zahar Editor, 1998.

TEIXEIRA, N. Porque escrevemos o livro "Conselhos a um nervoso". Correio do Povo. Porto Alegre, 27 de março de 1962. Editoriais, p. 4.

TENÓRIO, F. A reforma psiquiátrica brasileira, da década de 1980 aos dias atuais: história e conceito. História, Ciências, Saúde . Manguinhos, Rio de Janeiro, v. 9, n. 1, p. 25-59, jan.-abr. 2002.

\section{Endereço para correspondência}

Helena Beatriz Kochenborger Scarparo

Pontifícia Universidade Católica do Rio Grande do Sul, Av. Ipiranga, 6681, Prédio 11, sala 929, CEP 91530-000, Porto Alegre-RS, Brasil

Endereço eletrônico: scarparo@pucrs.br

Adolfo Pizzinato

Pontifícia Universidade Católica do Rio Grande do Sul , Av. Ipiranga, 6681, Prédio 11, sala 929, CEP 91530-000, Porto Alegre-RS, Brasil

Endereço eletrônico: adolfopizzinato@yahoo.com.br

Aline Accorssi

Pontifícia Universidade Católica do Rio Grande do Sul, Av. Ipiranga, 6681, Prédio 11, sala 929, CEP 91530-000, Porto Alegre-RS, Brasil

Endereço eletrônico:: alineaccorssi@gmail.com

Recebido em: 13/09/2010

Aceito para publicação em: 13/12/2010

Acompanhamento do processo editorial: Ana Maria Jacó-Vilela

\section{Notas}

*Doutoranda

${ }^{1}$ Pesquisa com apoio da FAPERGS e do CNPQ

${ }^{2}$ As narrativas aqui mencionadas fazem parte do acervo do Grupo de pesquisa "Psicologia e Políticas Sociais: memória, história e produção do presente". Todas pertencem a pesquisas aprovadas por comitês de ética. Além disso, por se tratar de pesquisa histórica, os entrevistados consentiram, através de termo escrito, na divulgação de seus nomes nas publicações geradas pelas investigações realizadas. 